\title{
A decade of the Common Drug Review
}

A decade after the Canadian Agency for Drugs and Technologies in Health (CADTH) took action to standardize drug coverage across the provinces, the armslength government-funded organization is now working to improve the system by enhancing transparency, reviewing drug classes and doing reviews in parallel with Health Canada.

Beginning next year, the Common Drug Review (CDR) will post full reports online for submissions received after Apr. 1, says CDR Director Dr. Chander Sehgal, who adds that they have "ramped up" the process of reviewing classes of drugs.

Now, instead of having two committees - one for class reviews and another for individual drugs - there is one committee: the Canadian Drug Expert Committee, responsible for all drug reviews, according to Sehgal.

Brian O'Rourke, president and CEO of CADTH, says class review "is something drug plans have been thinking about for a number of years." The most recent, says O'Rourke, reviewed oral anticoagulants. For now, the CDR is still limited to new drugs, but O'Rourke says they would consider old medications "if there was a question that came to us through the drug programs on the effectiveness or the safety."

"At market launch, there's still a lot of uncertainty on how that drug will work in the real world," says O'Rourke. The CDR examines the practicality of drugs based on efficacy and cost-effectiveness.

The CDR is also aiming for a more timely process by completing its reviews at the same time as Health Canada conducts its reviews, says O'Rourke.

According to O'Rourke and Sehgal, the benefit is faster output of recommendations. There is a risk of wasting resources if it's a "no" from Health Canada, they say, but that's only happened once.

Since its inception, the CDR has processed about 260 national recommendations on which prescription

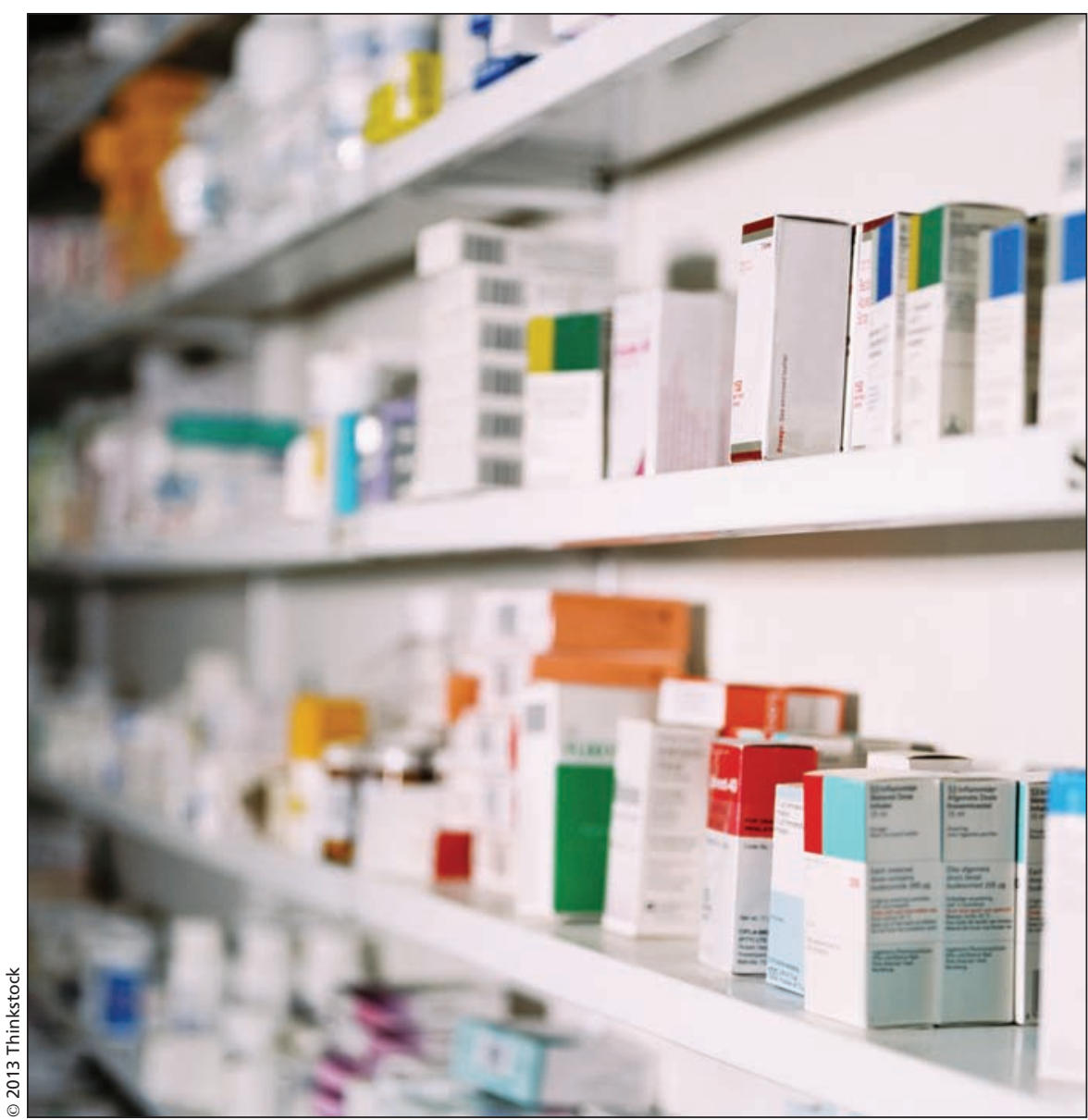

Whether or not a province decides to fund medications on pharmacy shelves is influenced by recommendations made by the Common Drug Review.

medications should be funded under provincial formularies, which saves the country from having to do the same review in every province and territory.

"Each province doesn't have the capacity to do full health-technology assessments," says Sehgal.

Before 2003, provinces had their own review boards, but the process was financially draining and wasted resources by repeating review processes. Studies published before 2003 found that prescription drug coverage varied widely across Canada (Med Care 2001;39:315-26.).

Health experts say a national standard is essential to establish value for taxpayer dollars.

"We're all Canadians. We all should have the same or similar drug coverage across the country," says Judy McPhee, director of pharmaceutical services at the Nova Scotia Department of Health and Wellness.

The review has been particularly effective in Atlantic Canada, where there are minimal resources for drug formularies. Leanne Jardine, director of pharmaceutical services at the New Brunswick Department of Health praised the national review for increasing the efficiency and transparency of the drug review process.

"When you pool the resources and the smart people across the country, it's amazing - and we get to benefit from that," she says.

Despite its success, some experts say there is still room for improvement. 
Amir Attaran, Canada Research Chair in Population and Public Health, at the University of Ottawa, Ontario, is particularly skeptical of the review. A paper he coauthored found that some provinces, such as Ontario and Alberta, only follow CDR recommendations about half the time (www.aims.ca/en /home/library/details.aspx/3286).

"You don't need a [review] to give you recommendations if those recommendations will be followed 50\% of the time. You could just flip a coin. It would cost a lot less and would give you equal fidelity," he says.

McPhee, however, disagreed.

"It's a bit misleading to say that provinces aren't following recommendations," she says. The smaller provinces are following recommendations, but larger provinces, like Ontario, that have their own resources, don't necessarily rely on the review for expertise and recommendations. Because of this, it could take them longer to follow CDR recommendations, says McPhee.

That delay is already on the radar for researchers. A 2010 study from the College of Pharmacy at Dalhousie University in Halifax, Nova Scotia suggested provinces support national reviews by aiming for a "more timely" consideration of recommendations (Health Policy 2010;5:100-14.)

But even if provinces abide by national recommendations, budget constraints and different population needs make it virtually impossible for complete cross-province consistency, says pharmaceutical policy expert Steve Morgan. "Our public drug plans are a loose patchwork that has no consistency across the country," according to Morgan, associate director of the University of British Columbia Centre for Health Services and Policy Research in Vancouver.

Another reason provinces may not follow national recommendations, Morgan says, is the fact that the list price on the market can now be bargained down based on the quantity a province buys.

Provinces with high patient volumes, such as Ontario, would be able to negotiate a lower price on a drug since the province is willing to buy a substantial amount of the medication.

However, the CDR must make recommendations based on the list price, and can only advise provinces that if a cost-reduction was factored into the cost-benefit analysis, the drug would be recommended.

Since there is no federal funding for drug coverage in Canada, the national review cannot bargain with pharmaceutical companies on behalf of the provinces.

Dr. Joel Lexchin, a professor in the school of Health Policy and Management at York University in Toronto, Ontario, says the CDR has done what it was asked, but that's not enough for standardizing pharmaceuticals cross-country.

"What we really need is federal leadership around the area of [funding] prescription drugs," he says. "If Ottawa was paying some of the cost, Ottawa would be much more concerned about which drugs are funded and what price they're funded at."

McPhee agrees that a national pharmacare program could help make cross-provincial coverage more consistent. But pharmaceutical and health policy experts suggest that isn't the CDR's responsibility.

For now, McPhee and others in the pharmaceutical industry are more concerned with expanding the review to include hospital medications and reviews of drugs already on the market. However, Sehgal says their resources are not enough for retroactive review. — Sarah Spitz, CMAJ

CMAJ 2013. DOI:10.1503/cmaj.109-4428 